\title{
Adaptation of Sensory Neurons to Hyalectin and Decorin Proteoglycans
}

\author{
Michele L. Lemons, ${ }^{1}$ Suman Barua, ${ }^{1}$ Michael L. Abanto, ${ }^{1}$ Willi Halfter, ${ }^{2}$ and Maureen L. Condic ${ }^{1}$ \\ ${ }^{1}$ Department of Neurobiology and Anatomy, University of Utah, School of Medicine, Salt Lake City, Utah 84132-3401, and ${ }^{2}$ Department of Neurobiology, \\ University of Pittsburgh, Pittsburgh, Pennsylvania 15261
}

\begin{abstract}
Proteoglycans are abundantly expressed in the pathways of developing and regenerating neurons, yet the responses of neurons to specific proteoglycans are not well characterized. We have shown previously that one chondroitin sulfate proteoglycan (CSPG), aggrecan, is potently inhibitory to sensory axon extension in short-term assays and that over time, embryonic neurons adapt to aggrecan-mediated inhibition through the transcriptional upregulation of integrin expression (Condic et al., 1999). Here, we have compared the response of embryonic sensory neurons to structurally distinct CSPGs that belong to either the hyalectin (or lectican) family of large, aggregating proteoglycans or the decorin (or small leucine-rich proteoglycan) family of smaller proteoglycans. Both of these structurally diverse proteoglycan families are expressed in developing embryos and inhibit outgrowth of embryonic sensory neurons in short-term cultures. These results document a previously uncharacterized inhibitory function for the decorin-family proteoglycan biglycan. Interestingly, embryonic neurons adapt to these diverse proteoglycans over time. Adaptation is associated with upregulation of select integrin $\alpha$ subunits in a proteoglycan-specific manner. Overexpression of specific integrin $\alpha$ subunits improves neuronal regeneration on some but not all decorin-family CSPGs, suggesting that neurons adapt to inhibition mediated by closely related proteoglycans using distinct mechanisms. Our findings indicate that CSPGs with diverse core proteins and distinct numbers of chondroitin sulfate substitution sites mediate a similar response in sensory neurons, suggesting that increased integrin expression may be an effective means of promoting axonal regeneration in the presence of diverse inhibitory proteoglycan species in vivo.
\end{abstract}

Key words: integrin; aggrecan; decorin; biglycan; versican; CSPG; chondroitin sulfate

\section{Introduction}

Many types of proteoglycans are expressed in early embryos, yet their precise role in neuronal development is controversial. Studies indicate that members of the chondroitin sulfate proteoglycan (CSPG) family can inhibit neurite outgrowth in vitro (Snow et al., 1990; Fichard et al., 1991; Snow and Letourneau, 1992; Braunewell et al., 1995; Maeda and Noda, 1996; Challacombe et al., 1997), and several in vivo studies show a correlation between an upregulation of CSPG staining and regeneration failure (McKeon et al., 1995; Gates et al., 1996; Davies et al., 1997; Fitch and Silver, 1997; Lemons et al., 1999; Silver and Miller, 2004). In contrast, other studies indicate that CSPGs are expressed in locations that support axon extension (for review, see Pearlman and Sheppard, 1996) and that CSPGs can constitute a permissive

Received Nov. 29, 2004; revised April 11, 2005; accepted April 12, 2005.

This work was supported by grants from the National Institutes of Health (R01 NS38138) and the McKnight Foundation to M.L.C. Antibodies were provided by the Developmental Studies Hybridoma Bank, developed under the auspices of the National Institute of Child Health and Human Development, and maintained by The University of lowa, Department of Biological Sciences (lowa City, IA). We thank Dr. S. A. Scott for critical comments on this manuscript and Anthony Cooke, Linda Cise, and Zachary Book for technical assistance.

Correspondence should be addressed to Dr. Maureen L. Condic, Department of Neurobiology and Anatomy, University of Utah, School of Medicine, 20 North 1900 East, Salt Lake City, UT 84132-3401. E-mail: mlcondic@neuro.utah.edu.

DOI:10.1523/JNEUROSCI.0773-05.2005

Copyright $\odot 2005$ Society for Neuroscience $\quad$ 0270-6474/05/254964-10\$15.00/0 substratum for axon outgrowth under some conditions in vitro (Streit et al., 1993; Faissner et al., 1994).

Some of the apparent contradictions between published studies may be attributable to distinct CSPG members having unique affects on neurite outgrowth. For example, the CSPG decorin inhibits neurite outgrowth (Yamada et al., 1994), whereas the CSPG biglycan has been reported to act as a neurotrophic molecule (Junghans et al., 1995; Koops et al., 1996). Thus, related proteoglycans may not necessarily have similar effects on neurite outgrowth.

The ability of embryonic neurons to adapt to proteoglycans over time may also contribute to the contradictions between published CSPG studies. Embryonic sensory neurons in vitro are initially inhibited on substrata containing laminin and the CSPG aggrecan, but outgrowth improves over time (Snow et al., 1990; Snow and Letourneau, 1992; Condic et al., 1999). In contrast, adult sensory neurons remain inhibited by an aggrecan-laminin environment in short-term assays in vitro (Condic, 2001) as well as in long-term assays in vivo (Lemons et al., 2003). Embryonic neurons compensate for inhibition by transcriptionally upregulating integrin receptor expression (Condic et al., 1999), whereas adult neurons do not (Condic, 2001). When adult integrin expression is increased experimentally, neurite extension in the presence of aggrecan is comparable with that of embryonic neurons (Condic, 2001). These results indicate that increasing integrin expression can essentially circumvent aggrecan-mediated 
inhibition, yet it is not clear whether other CSPGs are also inhibitory to axon extension and whether increasing integrin expression can also relieve this inhibition.

We have begun to characterize the response of embryonic neurons to select CSPGs. We have focused on CSPG members of two proteoglycan families that represent the extremes of proteoglycan structure: the hyalectin and decorin families (see Fig. 1A). Despite substantial differences in core protein sequence and in the number of chondroitin sulfate (CS) substitution sites, we found that members of both proteoglycan families are highly inhibitory to sensory neurite extension in short-term assays. Surprisingly, embryonic neurons adapt to the growth inhibitory effects of both hyalectin and decorin CSPGs through alterations in integrin expression. These findings suggest that increasing integrin expression can counteract the growth inhibitory influences of a wide range of proteoglycans expressed in the CNS after injury.

\section{Materials and Methods}

Cell culture and substratum preparation. Dorsal root ganglia (DRGs) were dissected from embryonic day 7 (E7) to E11 White Leghorn chicks and dissociated with brief trypsin treatment (Condic et al., 1999). Dissociated cells were preplated on tissue culture plastic in Ham's F-12 media containing $10 \%$ calf serum for $3 \mathrm{~h}$ at $37^{\circ} \mathrm{C}$ to remove more adherent nonneuronal cells (Barres et al., 1988). After $3 \mathrm{~h},>95 \%$ of cells selected were neuronal. Neurons were rinsed in PBS and cultured overnight on acidcleaned glass coverslips in serum-free media as described previously (Condic et al., 1999). NGF and neurotrophin 3 (NT3) were present in all cultures at $10 \mathrm{ng} / \mathrm{ml}$. Before neuronal plating, glass coverslips were coated with either laminin (Invitrogen, Carlsbad, CA) only or with a specific CSPG followed by laminin. Laminin-only coverslips were incubated for $1 \mathrm{~h}$ at room temperature with laminin (at $20 \mu \mathrm{g} / \mathrm{ml}$ ) in PBS. Aggrecan-, biglycan-, decorin- (Sigma, St. Louis, MO), and versican(Invitrogen) containing substrata were prepared by coating coverslips at the indicated CSPG concentrations in PBS for $1 \mathrm{~h}$, followed by laminin at $20 \mu \mathrm{g} / \mathrm{ml}$ for $1 \mathrm{~h}$ (Snow and Letourneau, 1992).

Radioactive labeling of proteins and protein binding. ${ }^{3} \mathrm{H}$-labeled laminin and ${ }^{14} \mathrm{C}$-labeled proteoglycans were made by reductive methylation using sodium cyanoborohydride according to a modification of published protocols (Jentoft and Dearborn, 1979; Herbst et al., 1988). Briefly, protein samples were dialyzed into $0.1 \mathrm{M}$ HEPES buffer at $4^{\circ} \mathrm{C}$ overnight and subsequently treated with a $20 \mathrm{~mm}$ sodium cyanoborohydride solution containing $1 \mathrm{~m} \mathrm{NaOH}$. $\left[{ }^{3} \mathrm{H}\right]$ Formaldehyde or $\left[{ }^{13} \mathrm{C}\right]$ formaldehyde (NEN, Boston, MA) was added to the proteins and allowed to incubate with shaking for $2 \mathrm{~h}$ at room temperature. Radioactively labeled proteins were then dialyzed against 1 m PBS and 10 mm EDTA. Protein concentrations were determined by spectophotometry, and radioactive labeling was determined by scintillation counting. Binding of laminin and proteoglycans to coverslips and 96-well plates (below) was determined by inclusion of ${ }^{3} \mathrm{H}$-labeled laminin and ${ }^{14} \mathrm{C}$-labeled proteoglycans at known specific activities in the coating medium, followed by extraction of the bound protein with $10 \%$ SDS and scintillation counting.

Immunohistochemistry analysis. The distribution of various proteoglycan species was examined by immunohistochemistry. Chick embryos (stages 23-25) were fixed in 4\% paraformaldehyde for $4 \mathrm{~h}$. The embryos were transferred through 5,15 , and 30\% dextrose solutions, embedded in OCT compound (Sakura Finetek, Torrance, CA), and cut at a thickness of $16 \mu \mathrm{m}$ on a cryostat. The sections were incubated for $20 \mathrm{~min}$ at room temperature in PBS buffer containing $0.1 \%$ Triton X-100. Primary antibodies (see below) were applied at 1:100 in normal goat serum (NGS) buffer (PBS with 5\% NGS and 0.1\% Triton X-100) for $1 \mathrm{~h}$. Sections were rinsed three times in PBS, and the appropriate secondary antibodies conjugated to Alexa 488 or 568 (Molecular Probes, Eugene, OR) were applied at 1:1000 in NGS buffer for $1 \mathrm{~h}$. Sections were rinsed and coverslipped in mounting media (Prolong; Molecular Probes). Immunohistochemical staining was visualized on a Nikon TE300 microscope equipped with fluorescent optics. Images were acquired with a cooled CCD camera using Spot acquisition software (Diagnostic Instruments, Sterling Heights, MI).

Primary antibodies. The 3A10 antibody [Developmental Studies Hybridoma Bank (DSHB), University of Iowa, Iowa City, IA], which recognizes a neurofilament-associated protein, was used to visualize motor and sensory axons. For immunohistochemistry, polyclonal antibodies against L1 were obtained from Dr. Vance Lemmon (University of Miami, School of Medicine, Miami, FL). For Western blot analysis, L1 was detected using the primary monoclonal antibody 8B8 (Halfter et al., 1994). Primary antibodies against decorin (CB-1) were obtained from DSHB. The monoclonal antibody against versican (MY-174) was obtained from Dr. D. Carrino (Case Western Reserve University, Cleveland, OH).

Three aggrecan antibodies were used in these studies. The S103L antibody was obtained from Dr. D. Carrino. Two monoclonal antibodies against aggrecan, $1 \mathrm{G} 12$ and 2B12, were generated by fusion of mouse spleen cells with X63Ag8.653 myeloma cells. The mice had been immunized with a crude proteoglycan fraction from E10 chick brain (Halfter et al., 1997). The antigen specificity of the antibodies was established by Western blots of chondroitinase-treated samples, cross-reactivity tests, and screening of a random-primed chick brain cDNA phage library (Stratagene, La Jolla, CA). The 2 and $2.5 \mathrm{~kb}$ cDNAs obtained by screening with the 2B12 monoclonal antibody started at nucleotides 1398 and 1577 of the full-length aggrecan cDNA sequence. The IG12 and the 2B12 antibodies were tested for cross-reactivity using immunoprecipitation. Membranes from two E10 chick embryos were solubilized in $1 \mathrm{ml}$ of $0.5 \%$ Triton X-100 in PBS, and the clarified extract was incubated with $2 \mathrm{~B} 12$ or $1 \mathrm{G} 12$ antibody for $1 \mathrm{~h}$. The antibody-antigen complex was precipitated by binding to $50 \mu \mathrm{l}$ of protein G-Sepharose 4B (Sigma). The Sepharose beads were spun down, washed three times in PBS/Triton $\mathrm{X}-100$, digested with $0.1 \mathrm{U}$ of chondroitinase $\mathrm{ABC}$ for $1 \mathrm{~h}$, and boiled in $100 \mu \mathrm{l}$ of SDS sample buffer. Protein precipitated with $1 \mathrm{G} 12$ was probed in Western blots with $2 \mathrm{~B} 12$ and protein precipitated with $2 \mathrm{~B} 12$ probed with $1 \mathrm{G} 12$. The same $\sim 400 \mathrm{kDa}$ band was seen in both experiments.

Nanomelic embryo identification. A premature stop codon in the aggrecan gene resulting in a truncated aggrecan core protein is present in nanomelic chickens (Li et al., 1993). However, the nanomelic phenotype of shortened and malformed limbs is not detected during early stages of development. Therefore, stage 25 nanomelic embryos were identified by immunohistochemistry. Animals were dissected, staged, imbedded, and sectioned to yield three sets of slides containing adjacent sections. One set of slides was stained with the S103L antibody, and the loss of S103L staining in the CNS (Domowicz et al., 1996) and notochord was used to identify nanomelic animals. The remaining two sets of adjacent sections were stained with $1 \mathrm{G} 12$ and 2B12 antibodies as shown.

Western blot analysis. Aggrecan was detected in crude membrane preparations of chick brain or in urea extracts from brain and cartilage tissue. For membrane preparations, E10 chick brain homogenate was centrifuged at $1000 \mathrm{rpm}$ to pellet the nuclei. The supernatant was spun at $10,000 \mathrm{rpm}$, and the high-speed membrane pellet was used for analysis. For urea extracts, E10 brain and cartilage were extracted with PBS and spun at 10,000 rpm. The pellets were reextracted with $8 \mathrm{~m}$ urea in PBS, and these urea extracts were used as samples. All samples were digested with $0.1 \mathrm{U}$ of chondroitinase $\mathrm{ABC}$ for $1 \mathrm{~h}$, separated in $3.5-15 \%$ gradient SDS-PAGE, and blotted onto nitrocellulose. Aggrecan was detected using 1 G12 and 2B12 primary antibodies followed by alkaline phosphataselabeled goat anti-mouse secondary antibodies (Jackson ImmunoResearch, West Grove, PA).

PCR analysis. mRNA was extracted from stage 23 (E3.5-4.0) chick DRGs, spinal cords, notochords, and E11 brain using Oligotex Direct (Qiagen, Hilden, Germany). Isolated mRNA was reverse transcribed into cDNA using the Superscript First-Strand Synthesis kit (Invitrogen). Control primer sequences were designed to amplify a 300 bp product of chicken glyceraldehyde-3-phosphatase dehydrogenase (GAPDH). The sense primer used for GAPDH was AGTCGGAGTCAACGGATTG, and the antisense primer was TCTCCATGGTGGTAAGACA. Specific primers for aggrecan were designed on the basis of the White Leghorn aggrecan sequence to amplify an 823 bp product. The primers were BLASTED to ensure that they would not amplify other known sequences. The aggrecan sense primer used was CTGCCAGGTGTATGGGACTT. The ag- 
grecan antisense primer was TGGCGTAGAAGACTTTGCCT. PCR products were visualized on a $2.5 \%$ agarose gel stained with ethidium bromide and confirmed by sequencing. Sequencing of the aggrecan PCR product confirmed the highest identity with White Leghorn aggrecan (100\%).

Cell adhesion assays. Cells were cultured overnight on laminin-coated coverslips and removed from the substratum by a brief treatment with calcium-free media and gentle scraping in media containing $10 \%$ serum at $4^{\circ} \mathrm{C}$ to prevent the internalization of cell surface integrins. Cells were spun down at $4^{\circ} \mathrm{C}$, resuspended in serum-free media, and maintained at $4^{\circ} \mathrm{C}$ until plating. To measure cell adhesion, 96-well plastic plates (Thermo Lab Systems, Waltham, MA) were coated with CSPGs followed by laminin (as described above). The CSPG/laminin-coated plates were rinsed, blocked with PBS containing $5 \mathrm{mg} / \mathrm{ml} \mathrm{BSA}$ and $0.2 \%$ sodium azide for $1 \mathrm{~h}$, and rinsed extensively with PBS. Cells were applied at 10,000 cells/well and allowed to adhere for $3 \mathrm{~h}$ at $37^{\circ} \mathrm{C}$. Wells were rinsed once with $100 \mu$ lof PBS and incubated for $10 \mathrm{~min}$ in PBS containing $2 \mu \mathrm{g} / \mathrm{ml}$ 2',7'-bis-(2-carboxyethyl)-5-(and-6)-carboxyfluorescein acetoxymethyl ester (Molecular Probes), followed by detection of fluorescein emission using a microplate fluorescence reader (Bio-Rad, Hercules, CA).

Time-lapse analysis. To determine the rate of neurite extension, cells were cultured as described above on either laminin or proteoglycan/ laminin substrata for 3 or $20-24 \mathrm{~h}$ and moved to a heated microscope stage. For each of the proteoglycans studied, a single concentration was selected for time-lapse analysis based on the proteoglycan concentration that inhibited cell attachment between 50 and $80 \%$ in cell adhesion assays. The applied concentrations were as follows: aggrecan, $50 \mu \mathrm{g} / \mathrm{ml}$; biglycan, $25 \mu \mathrm{g} / \mathrm{ml}$; decorin, $12.5 \mu \mathrm{g} / \mathrm{ml}$. Protein binding was determined for both laminin (applied after proteoglycans at $20 \mu \mathrm{g} / \mathrm{ml}$ ) and proteoglycans using radioactively labeled protein (see above). Bound laminin was $0.3 \mu \mathrm{g} / \mathrm{cm}^{2}$ for all conditions, aggrecan was $0.29 \mu \mathrm{g} / \mathrm{cm}^{2}$, biglycan was $0.28 \mu \mathrm{g} / \mathrm{cm}^{2}$, and decorin was $0.31 \mu \mathrm{g} / \mathrm{cm}^{2}$. Unlike cell adhesion assays, time-lapse dishes were not washed after cell plating to remove weakly adherent cells; thus, a similar number of cells were observed in all conditions. After the dishes were moved to a heated microscope stage, they were allowed to equilibrate for $15 \mathrm{~min}$, and then images were captured for $1 \mathrm{~h}$, one image every $5 \mathrm{~min}$. The rate of axon extension was determined by dividing the distance traversed by the growth cone (as measured from the leading edge of the growth cone) by the elapsed time, as determined using MetaMorph Imaging Series 5.0 software (A. G. Heinze, Valencia, CA).

Surface expression of integrins. Cell surface receptors were labeled with biotin and immunoprecipitated using published methods and antibodies specific for integrin- $\alpha$ subunits, as described previously (Condic et al., 1999). Immunoprecipitated proteins were size fractionated under nonreducing conditions on acrylamide gels and transferred to nitrocellulose membrane using standard protocols. Biotin-labeled proteins were detected using strepavidin conjugated to HRP and a chemoluminescent reagent (Pierce, Rockford, IL), followed by exposure to film. The ratios of protein determined from quantification of film were comparable with those obtained by direct phosphorimaging of chemoluminescently detected proteins (data not shown).

Before immunoprecipitation, micro-BCA protein analysis (Pierce) was used to determine equal protein concentration of each sample, as published previously (Condic and Letourneau, 1997; Condic et al., 1999; Condic, 2001). This means of determining protein loading into each immunoprecipitation is both highly accurate and reproducible [ $\alpha$-tubulin band intensities from multiple immunoprecipitation lysates vary by $<10 \%$; for example, see Strachan and Condic (2004)].

Integrin overexpression. The pMES plasmid (kindly provided by C. E. Krull, University of Michigan, Ann Arbor, MI) contains a chick $\beta$-actin promoter followed by a multiple cloning site, an internal ribosome entry site sequence, and an enhanced green fluorescent protein (GFP) sequence. pMES $\alpha 6$ and pMES $\alpha 3$ were constructed by inserting human integrins $\alpha 6$ and $\alpha 3$ into the multiple cloning site of pMES.

One hundred eighty DRGs were dissected from E8 embryos and dissociated with trypsin. Cells were suspended in $8 \mathrm{ml}$ of F12H (Invitrogen) and divided into two $4 \mathrm{ml}$ aliquots. Both aliquots were spun down at 3000 rpm for $5 \mathrm{~min}$, and supernatants were removed. Cells were transfected immediately using electroporation (Amaxa, Gaithersburg, MD) according to the manufacturer's instructions. Neurons were transfected with either $4 \mu \mathrm{g}$ of pmax-GFP construct (Amaxa) alone (controls) or with 2 $\mu \mathrm{g}$ of pmax-GFP in combination with either $2 \mu \mathrm{g}$ of integrin $\alpha 3$ or $\alpha 6$ pMES. After transfection, cells were preplated for $3 \mathrm{~h}$ on $100 \mathrm{~mm}$ Falcon tissue culture dishes in $\mathrm{F} 12 \mathrm{H}$ with $10 \%$ fetal calf serum. Cells were pelleted (3000 rpm, $5 \mathrm{~min}$ ), resuspended in F12H supplemented with NGF and NT3, and plated overnight on $100 \mathrm{~mm}$ dishes that had been pretreated with $10 \mathrm{ml}$ of $1 \%$ BSA in calcium magnesium-free PBS for $1 \mathrm{~h}$ to prevent adhesion of cells. Cell surface expression of human integrin subunits was confirmed by staining live with appropriate human-specific antibodies (Chemicon, Temecula, CA).

After overnight culture, GFP expression was readily detectable. Neurons were transferred to laminin or laminin/proteoglycan-coated coverslips and filmed as described above (see above, Time-lapse analysis) after $3 \mathrm{~h}$ in culture. A fluorescent image was taken immediately before beginning the time-lapse filming to identify transfected cells.

\section{Results \\ Distribution of decorin and hyalectin proteoglycans in embryos}

Decorin and hyalectin CSPGs are structurally quite divergent (Fig. $1 A$ ). CSPGs belonging to the hyalectin family include aggrecan and versican. Like all hyalectins, aggrecan and versican are large proteoglycans with numerous CS substitution sites (Fig. $1 A$ ). In contrast, CSPG members of the decorin family (decorin and biglycan) are smaller and have fewer CS substitution sites (Fig. 1A). Although all CSPGs share a common feature of having at least one CS substitution site, each CSPG has a distinct core protein sequence and can be functionally very different from each other.

Hyalectin and decorin family members are abundant in tissues encountered by sensory axons as they extend (Fig. $1 B-F$ ). As reported previously (Fernandez et al., 1991; Landolt et al., 1995), versican (a hyalectin proteoglycan) is expressed in areas of the embryo that are avoided by extending sensory and motor axons at stage 23 (Fig. 1C) (e.g., in the region surrounding the notochord). Interestingly, perinotochordal versican staining appears stronger on the dorsal side of the notochord. Versican staining is also present in the dorsal spinal cord (Fig. 1C) and forming cartilage of the limb (data not shown). Like versican, decorin is expressed in developing cartilage (Fernandez et al., 1991; Lennon et al., 1991) as well as the perinotochordal region (Fig. 1D), suggesting that both decorin and versican may play a role in defining regions of the embryo that repel sensory growth cones. Decorin is also expressed in the skin (Fig. 1E) (Lennon et al., 1991), a major target of sensory afferents that is first innervated starting at stage 25 , suggesting decorin may contribute to the arrest of cutaneous afferents in the skin and their failure to invade the epidermis (Cahoon and Scott, 1999).

Although chicken biglycan has thus far not been cloned, embryonic chick tissue expresses a biglycanated form of decorin that is structurally very similar to biglycan and that may serve many of the same functions (Blaschke et al., 1996). The antibody against chicken decorin used in this study (Lennon et al., 1991) recognizes both the single and the biglycanated (biglycan-like) form of decorin (D. Carrino, personal communication).

The distribution of aggrecan (a hyalectin proteoglycan) in developing chick tissues is more complex. The S103L antibody that recognizes aggrecan reveals expression of this proteoglycan in the notochord, perinotochordal mesenchyme (Fig. 1F), and in the condensing cartilage of the limb (data not shown), as reported previously (Domowicz et al., 1995). Interestingly, a second monoclonal antibody, 2B12, revealed aggrecan-like immu- 
A

\section{Hyalectin}
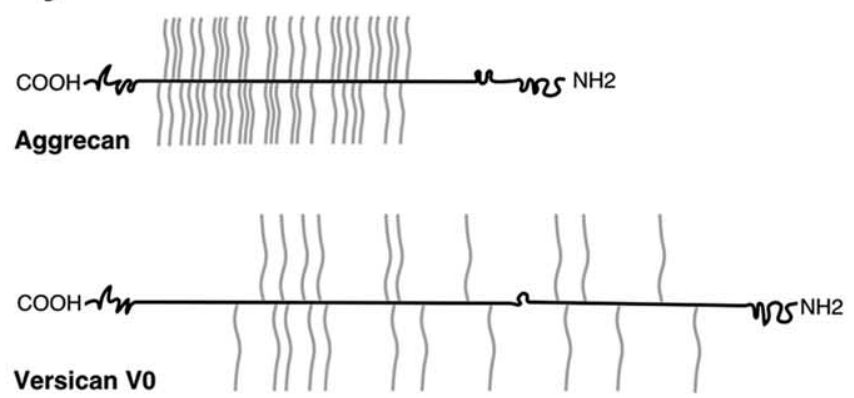

\section{Decorin}
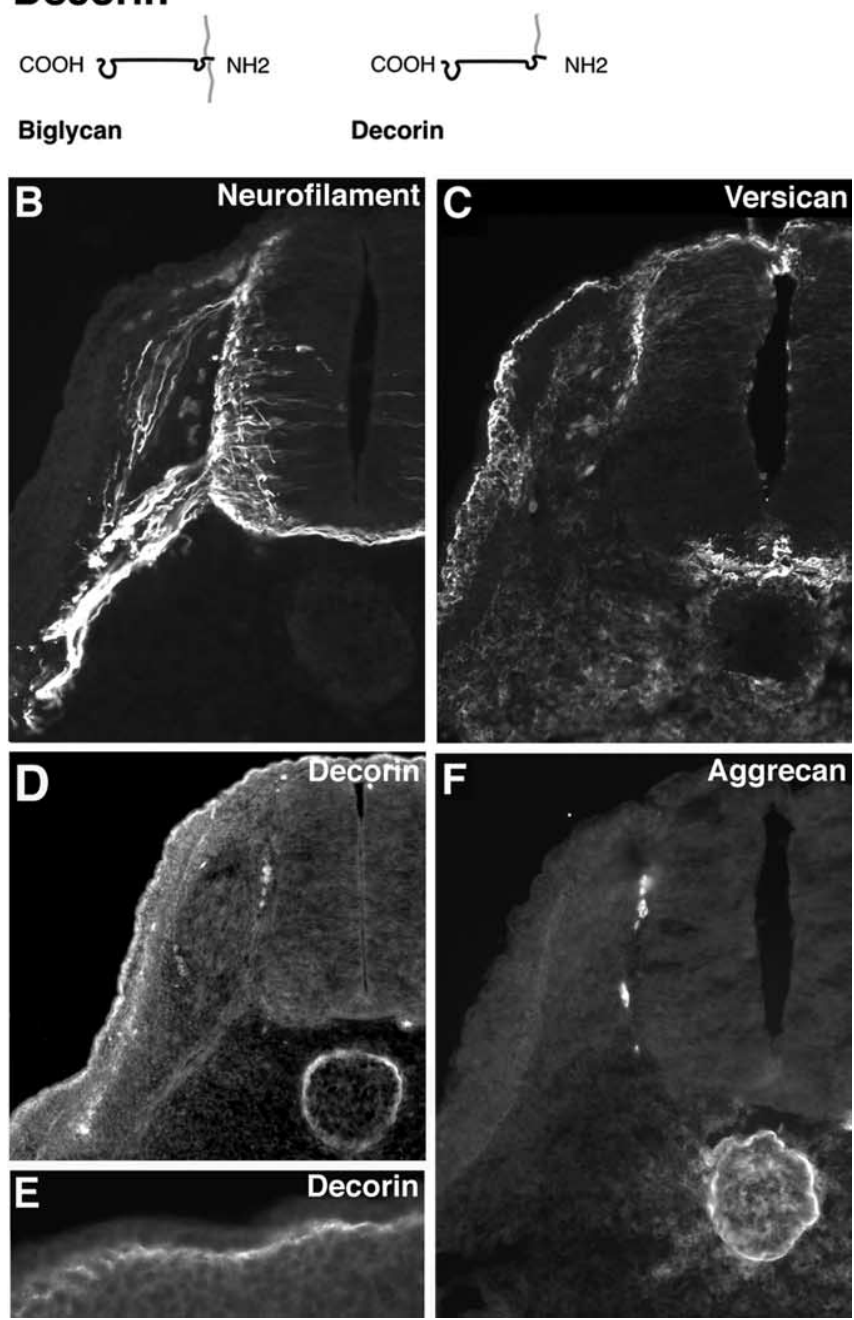

Figure 1. Structurally diverse hyalectin and decorin CSPGs are present during sensory axon outgrowth. $A$, Schematic diagram illustrates the range of core protein sizes and $C S$ substitution patterns of hyalectin and decorin proteoglycans [adapted from Condic and Lemons (2002)]. Hyalectin proteoglycans are large proteoglycans with numerous CS substitution sites. In contrast, decorin proteoglycans are smaller and have fewer $C S$ substitution sites. The two members of the decorin family expressed in the nervous system bear only one (decorin) or two (biglycan) CS side chains (Fransson et al., 2000). $\mathrm{COOH}, \mathrm{C}$ terminus; NH2, N terminus. B-F, Adjacent lumbar cross sections of chick embryos at stage $23(\mathrm{E} 3.5-\mathrm{E} 4 ; \boldsymbol{B}, \boldsymbol{C}, \boldsymbol{F})$ and stage $25(\mathrm{E} 4.5 ; \boldsymbol{D}, \boldsymbol{E})$ processed for immunohistochemistry. $\boldsymbol{B}$, Anti-neurofilament-associated protein staining with the $3 \mathrm{~A} 10$ antibody reveals the presence of sensory and motor axons. C, An anti-versican antibody (MY174) reveals staining in the skin and surrounding the notochord. Diffuse versican staining is also seen throughout the mesenchyme and in the dorsal spinal cord. D, Low-magnification view noreactivity in the nervous system, particularly in the ventral horn of the spinal cord, the oval bundle of His (the presumptive dorsal funiculus), and along the peripheral nerve (Fig. $2 A$ ). This pattern of staining is very similar to aggrecan staining reported in embryonic rat spinal cord (Popp et al., 2003). Because the staining pattern of the $2 \mathrm{~B} 12$ antibody was so different from that observed with the S103L antibody (Fig. $1 F$ ), we also characterized the epitope recognized by the $2 \mathrm{~B} 12$ antibody.

The 2B12 antibody recognizes a single band of $\sim 400 \mathrm{kDa}$ in chondroitinase $\mathrm{ABC}$-treated extracts from brain and cartilage tissue (Fig. $2 B$ ). The size of the protein band is consistent with the reported size of chondroitinase-treated chick aggrecan. The 2B12 antibody also recognizes an $\sim 400 \mathrm{kDa}$ band in brain plasma membrane preparations (Fig. 2B). Moreover, both 2B12 and another chicken aggrecan antibody, 1G12, cross-react; chondroitinase-treated protein that had been immunoprecipitated by $2 \mathrm{~B} 12$ was recognized on Western blots by the 1G12 antibody, and 1G12 immunoprecipitated protein was recognized by 2B12 (data not shown). These data suggest that the pattern of immunoreactivity we observe with the $2 \mathrm{~B} 12$ antibody reflects the distribution of a novel aggrecan epitope that is not recognized by other antibodies that recognize cartilage and notochordassociated aggrecan, including S103L. Although the distribution of the 2B12 antigen was reminiscent of the neuronal cell adhesion molecule L1 at this stage (Thiery et al., 1985; Daniloff et al., 1986), 2B12 did not recognize L1 on Western blots (Fig. 2 B), and sections double stained for $2 \mathrm{~B} 12$ and $\mathrm{L} 1$ showed overlapping but distinct patterns of immunoreactivity (data not shown).

We examined the cellular basis for nervous system-associated 2B12/aggrecan-like immunoreactivity in three ways. First, we examined the expression of aggrecan mRNA by reverse transcription (RT)-PCR (Fig. 2C). Cells of the spinal cord and notochord at stage 23 (E3.5-E4) express aggrecan at high levels, whereas sensory ganglia show low levels of aggrecan message. Second, we found that cultured sensory neurons stain weakly with the $2 \mathrm{~B} 12$ antibody (Fig. $2 D, E$ ), suggesting these neurons can express the 2B12 antigen. Finally, we examined 2B12 staining in nanomelic chicken embryos. Nanomelic chickens have a premature stop codon in the aggrecan gene that results in a truncated aggrecan core protein expressed in both cartilage and neurons ( $\mathrm{Li}$ et al., 1993; Domowicz et al., 1995). In nanomelic chondrocytes, the truncated aggrecan protein is not processed or secreted correctly, making nanomelics essentially an aggrecan protein-null mutation in this tissue (Domowicz et al., 2000; Chen et al., 2002). The $1 \mathrm{G} 12$ antibody staining in the notochord (Fig. $2 F$ ) is very similar to $\mathrm{S} 1031$ staining (Fig. $1 F$ ). In nanomelic embryos, 1G12 staining (Fig. 2G) and S103L staining (Domowicz et al., 2003) (data not shown) are lost. The $2 \mathrm{~B} 12$ antibody notochord-associated staining is also lost in nanomelic animals (Fig. $2 H$ ), suggesting that this antibody recognizes notochord-associated aggrecan. However, nervous system-associated $2 \mathrm{~B} 12$ staining persists in nanomelic animals (Fig. $2 \mathrm{H}$ ), suggesting either $2 \mathrm{~B} 12$ recognizes a truncated aggrecan protein synthesized by neurons or that the 2B12 antibody recognizes both aggrecan and a related molecule.

$\leftarrow$

showing decorin immunoreactivity (labeled by antibody $(B-1)$ in the skin, dermomyotome, and surrounding the notochord. $\boldsymbol{E}$, Higher-magnification view showing decorin expression in the skin. $\boldsymbol{F}$, Anti-aggrecan antibody S103L shows aggrecan is present in and surrounding the notochord. 
The observation that neither the S103L antibody or the 1 G12 antibody detected aggrecan protein in the spinal cord or DRG, locations where aggrecan message is present (Fig. 2C), suggests either that these tissues do not translate aggrecan message or that they produce a form of aggrecan that is not reliably detected by the S103L and $1 \mathrm{G} 12$ antibodies.

\section{Hyalectin and decorin proteoglycans inhibit neuronal adhesion}

The ability of specific proteoglycans to inhibit the attachment of embryonic sensory neurons to laminin was determined in short-term adhesion assays. Attachment is a necessary first step for extension of neurites, and efficiency of cell adhesion often predicts efficiency of axon extension. The large hyalectin proteoglycans, aggrecan and versican, efficiently inhibited neuronal attachment (Fig. 3A). Surprisingly, the smaller proteoglycans, biglycan (Fig. $3 B$ ) and decorin (Fig. 3C), strongly inhibited neuronal attachment also.

Our data show that $>90 \%$ inhibition of attachment by aggrecan (Fig. 3A) occurs at applied concentrations that result in $\sim 0.298 \mu \mathrm{g} / \mathrm{cm}^{2}$ aggrecan bound to the substratum (with the size of aggrecan being $>2500 \mathrm{kDa}$, this corresponds to $\sim 0.2$ $\mathrm{nM}$ aggrecan $/ \mathrm{cm}^{2}$; see Materials and Methods). In contrast, a comparable level of inhibition of attachment (i.e., $>90 \%$ ) was obtained with plating concentrations of decorin (Fig. 3C) that result in a bound concentration of $0.333 \mu \mathrm{g} / \mathrm{cm}^{2}$ decorin (with the size of decorin being $100 \mathrm{kDa}$, this corresponds to $\sim 3.3 \mathrm{~nm}$ bound decorin $/ \mathrm{cm}^{2}$ ), an $\sim 10$-fold higher molar concentration than required for aggrecan. Given that aggrecan is composed of 90\% CS (w/w) and 10\% core glycoprotein (w/ $\mathrm{w}$ ), whereas only $\sim 60 \%$ of the molecular weight of decorin is attributable to CS chains, the concentration of bound-CS differs by $<30 \%$ between the two conditions $\left(\sim 0.20 \mu \mathrm{g} / \mathrm{cm}^{2}\right.$ bound CS for decorin and $0.27 \mu \mathrm{g} / \mathrm{cm}^{2}$ bound CS for aggrecan).

\section{Inhibition of sensory neurite extension} by CSPGs is followed by adaptation

The outgrowth of neurites in short-term assays was also inhibited by the presence of proteoglycans. When embryonic sensory neurons were cultured on substrata containing laminin and proteoglycans, the number of neurites extended at $3 \mathrm{~h}$ in culture was greatly suppressed relative to substrata containing laminin alone. By $20-24 \mathrm{~h}$ in culture, however, numerous fibers had been extended on substrata containing proteoglycans (Fig. 4), some of which were fasciculated, as seen previously (Snow et al., 2003).

To determine whether the difference in fiber outgrowth we

C
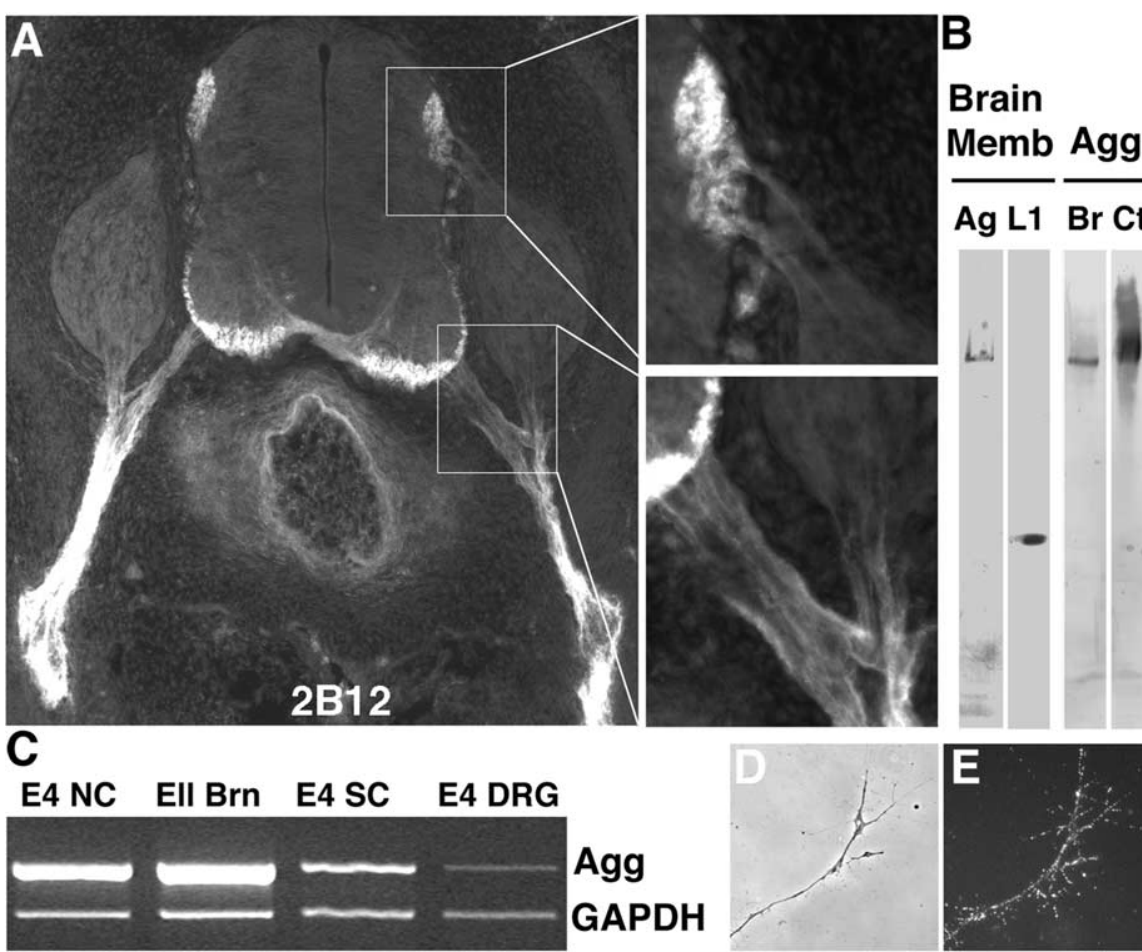

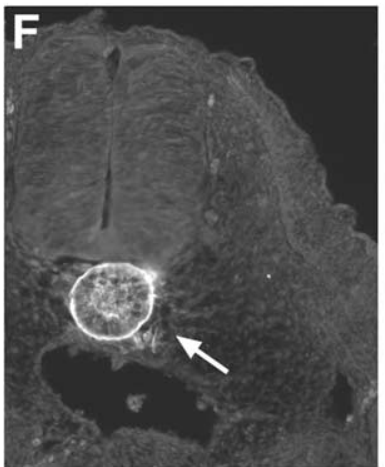

1G12: Wt

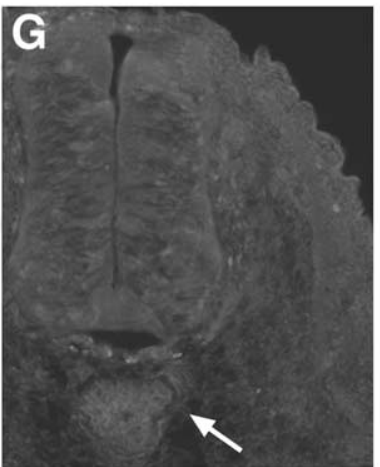

1G12: $\mathrm{Nm}$
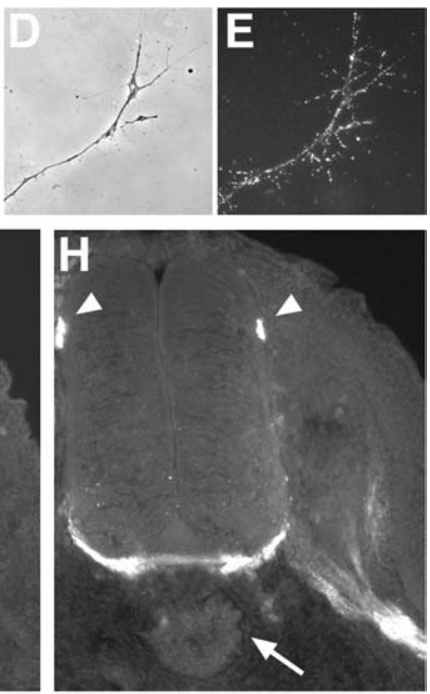

2B12: $\mathrm{Nm}$
Figure 2. Monoclonal aggrecan antibodies reveal distinct patterns of immunoreactivity in the notochord and nervous system. $\boldsymbol{A}$, Cross section of a stage 24 chick embryo (wild type) stained with monoclonal 2B12 shows immunoreactivity in the peripheral nerve, ventral spinal cord, oval bundle of His, and notochord. The oval bundle of His (top box) and ventral root (bottom box) are enlarged in the right panels. $\boldsymbol{B}$, Western blot analysis indicates monoclonal $2 \mathrm{~B} 12$ antibody recognizes a single band of appropriate molecular size for the aggrecan core protein $(\mathrm{Ag})$ in preparations of brain membranes (Brain Memb) treated with chondroitinase $A B C$. $L 1$ is also highly expressed in brain membrane preparations, but $2 B 12$ does not recognize a band the same size as $L 1$. The $2 B 12$ antibody also recognizes a similar size band in chondroitinase $A B C$-treated urea extracts from the brain (Br). The $2 B 12$ antibody identifies a slightly higher molecular weight smear in chondroitinase $A B C$-treated urea extracts from cartilage $(C t)$, consistent with the known keratan sulfate chains present on cartilage-derived aggrecan. C, Aggrecan message is detected by RT-PCR in samples of E4 notochord (E4 NC), spinal cord (E4 SC), and DRG (E4 DRG) as well as E11 brain (E11 Brn). D, E, Corresponding phase and fluorescent images of a cultured sensory growth cone that is lightly stained with $2 \mathrm{~B} 12$ antibody. $\boldsymbol{F}$ - $\boldsymbol{H}$, Wild-type (Wt) and nanomelic (Nm) embryos at stage 22 are immunostained with anti-aggrecan monoclonal antibodies $1 \mathrm{G} 12$ and $2 \mathrm{~B} 12$.F, The $1 \mathrm{G} 12$ antibody reveals notochord-associated aggrecan staining (arrow) in wild-type animals, similar to the pattern seen with the monoclonal S103L antibody (see Fig. 1F). G, In nanomelic animals, $1 \mathrm{G} 12$ immunostaining is not expressed, as is also the case for the S103L antibody (Domowicz et al., 2003). The arrow points to $1 \mathrm{G} 12$-negative notochord. $\boldsymbol{H}$, In an adjacent cross section to that shown in G, the 2B12 antigen is detected in the ventral spinal cord, oval bundle of His (arrowheads), and ventral roots of nanomelic embryos but not in notochord (arrow). Agg, Aggrecan.

observed at $3 \mathrm{~h}$ compared with $20-24 \mathrm{~h}$ in culture was attributable to distinct rates of growth cone extension, cultures were examined using time-lapse video microscopy. In agreement with previous studies (Condic et al., 1999), the rate of neurite extension in the presence of aggrecan was greatly reduced at $3 \mathrm{~h}$ in culture but was indistinguishable from the rate observed on laminin alone by $20-24 \mathrm{~h}$ (Fig. $5 \mathrm{~A}$ ). A similar pattern of initial inhi- 
A.

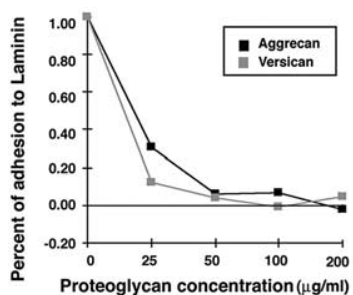

B.

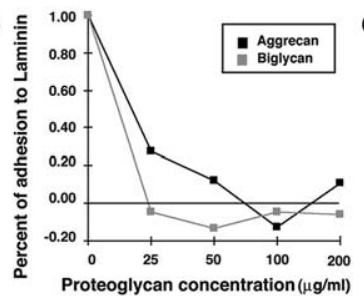

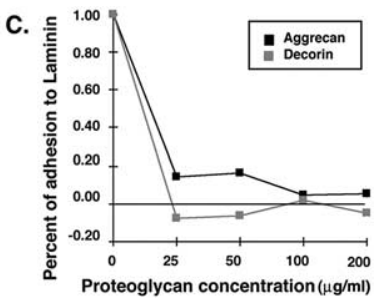

Figure 3. CSPGs with diverse structure and unique core proteins inhibit the attachment of embryonic sensory neurons to laminin. Substrata were coated with the indicated concentrations of proteoglycan, followed by $20 \mu \mathrm{g} / \mathrm{ml} \mathrm{laminin}$. At all proteoglycan concentrations, laminin binding was constant (see Materials and Methods). Attachment of neurons after $3 \mathrm{~h}$ in culture is expressed as a percentage of control attachment to laminin. Inhibition of attachment to substrata containing versican $(\boldsymbol{A})$, biglycan $(\boldsymbol{B})$, and decorin $(\boldsymbol{C})$ were similar to inhibition by aggrecan (black lines in all panels). Similar results were seen in at least three experiments, with data from a typical experiment shown.

3 hours

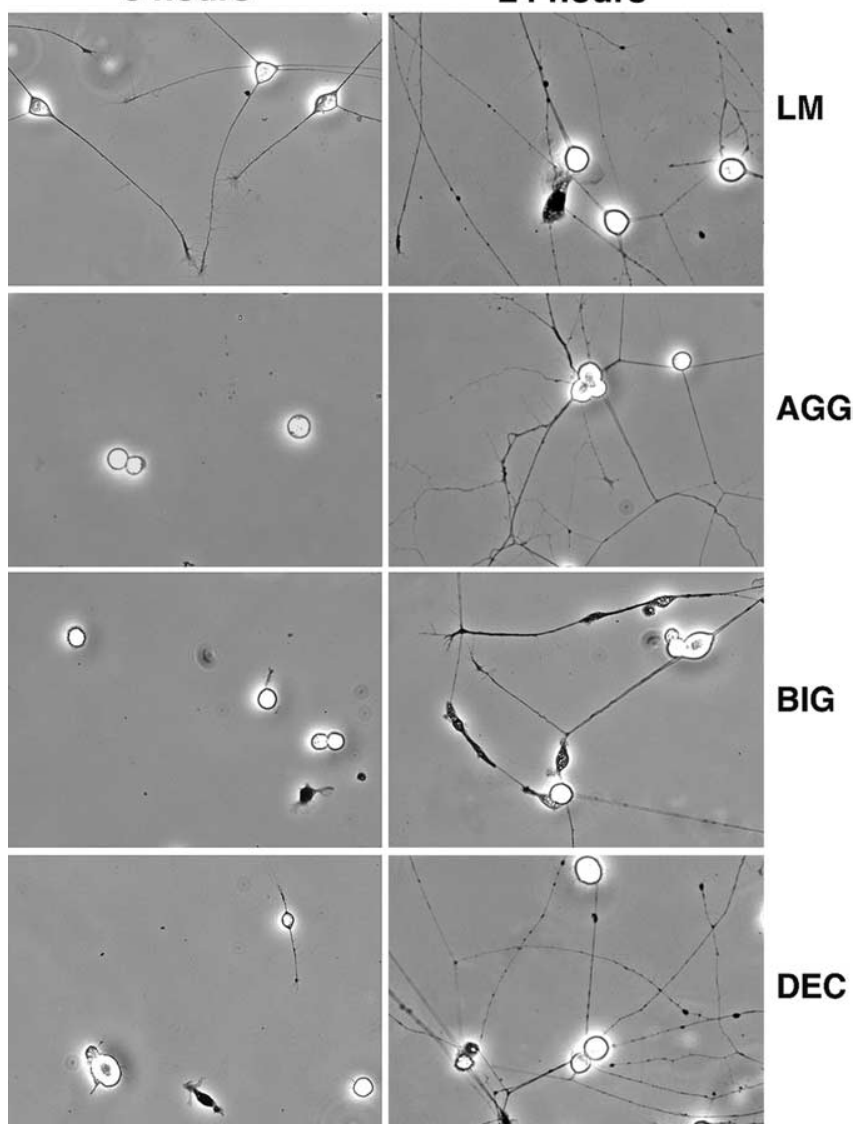

Figure 4. Extension of neurites on substrata containing laminin and proteoglycan is initially inhibited but recovers by $20-24 \mathrm{~h}$ in culture. Phase micrographs of neurons cultured on laminin alone or on substrata containing both laminin and proteoglycan. LM, Laminin; AGG, aggrecan/ laminin; BIG, biglycan/laminin; DEC, decorin/laminin. Representative phase images are shown at 3 and $24 \mathrm{~h}$ in culture.

bition followed by adaptation was also observed with two members of the decorin family (decorin and biglycan). At $3 \mathrm{~h}$ in culture, the rate of growth cone extension was reduced on decorin and biglycan, but by $20-24 \mathrm{~h}$ in culture, the rate of growth cone extension on these proteoglycan/laminin substrata was indistinguishable from laminin alone (Fig. $5 B, C$ ). These results indicate that CSPGs with diverse molecular structure inhibit both attachment and neurite extension in short-term cultures and that embryonic neurons adapt to this inhibition over time.
Upregulation of integrin expression is correlated with adaptation

Previous work has shown that adaptation to aggrecan is attributable at least in part to the upregulation of integrin receptors, enabling neurons to extend processes despite the presence of this inhibitory proteoglycan (Condic et al., 1999; Condic, 2001). We examined the expression of integrin receptors on neurons that were cultured in the presence of laminin alone or laminin in combination with distinct inhibitory proteoglycans (Fig. 6). These current studies differ from previous studies because the proteoglycans examined here are distinct from aggrecan (and from each other) in both their core protein sequence, number of CS substitution sites, and spatial patterning in the chick embryo (Fig. 1). At $20-24 \mathrm{~h}$ in culture, cell surface expression of three receptors for laminin (receptors containing integrins $\alpha 1, \alpha 3$, and $\alpha 6$ ) increases in neurons cultured on proteoglycan/laminin substrata compared with neurons cultured on laminin alone, with the one exception: cell surface integrin $\alpha 6$ expression is not increased on neurons in the presence of biglycan (Fig. 6).

\section{Integrin overexpression enables neurite extension in the presence of inhibitors}

To determine whether upregulation of integrin expression is sufficient to mediate adaptation of neurons to inhibitory proteoglycans in culture, we examined the rates of axon extension in neurons that had been transiently transfected with constructs expressing human integrin $\alpha$ subunits and GFP as a marker for transfection (Fig. 7A). When neurons overexpressing integrin $\alpha 3$ were examined at $3 \mathrm{~h}$ after plating on proteoglycan/laminin substrata, their rates of axon extension were identical to those observed on laminin alone, whereas neurons expressing control constructs were strongly inhibited. Thus, overexpression of a single integrin subunit $(\alpha 3)$ in culture relieves the inhibition of neurite extension by diverse inhibitory proteoglycan molecules. In contrast, outgrowth improved on decorin but not on biglycan substrata after transgenic expression of integrin $\alpha 6$ (Fig. 7B). Interestingly, neurons endogenously upregulate expression of $\alpha 6$ when cultured on decorin but not on biglycan substrata (Fig. 6). Although these cultures are primarily neuronal $(>95 \%)$, it is likely that satellite cells are present in low numbers. However, it is not likely that satellite cells contribute to the adaptation of integrin-transfected neurons seen at $3 \mathrm{~h}$ after plating, because nontransfected cells (also in the presence of the same satellite cells) do not adapt. Together, these studies suggest that integrin subunits that are endogenously regulated by embryonic neurons effectively improve neurite outgrowth in short-term culture assays.

\section{Discussion}

Members of the decorin and hyalectin proteoglycan families are expressed in tissues encountered by sensory axons during development, but the response of embryonic neurons to specific proteoglycans has been unclear. Here, we demonstrate that proteoglycans with divergent core-protein sequences, varying degrees of CS substitution, and contrasting sizes are strongly inhibitory to sensory neuron attachment and neurite extension in short-term assays. Embryonic neurons adapt to proteoglycan-mediated inhibition; between $20-24 \mathrm{~h}$, neurons cultured in the presence of 
proteoglycan are able to extend axons at the same rate observed on laminin alone. The behavioral adaptation of neurons is correlated with a proteoglycan-specific increase in surface expression of at least three laminin receptors: integrins $\alpha 1 \beta 1$, $\alpha 3 \beta 1$, and $\alpha 6 \beta 1$. Overexpression of these integrin receptors enables neurons to extend processes in short-term culture assays, also in a proteoglycan-specific manner. Our results indicate that embryonic neurons can overcome the inhibitory influence of distinct proteoglycans through increased expression of laminin receptors.

These data suggest that regulated integrin expression may be a mechanism through which embryonic neurons accommodate diverse inhibitory environments during development and regeneration.

\section{Aggrecan expression in the nervous system}

Aggrecan is present in the spinal cord (Lemons et al., 2001; Popp et al., 2003), brain (Milev et al., 1998), DRGs, and peripheral nerve of rats (Popp et al., 2003). The pattern of aggrecan immunoreactivity recently reported in embryonic rat spinal cord (Popp et al., 2003) is nearly identical to the pattern we observed in the chick embryo using one of three monoclonal antibodies, 2B12 (Fig. 2). Both the 2B12 antibody and the one used by Popp et al. (2003) reveal staining in the oval bundle of His, DRGs, and peripheral nerve. The $2 \mathrm{~B} 12$ antibody nerve-associated staining could be attributable to expression by sensory axons, motor axons, Schwann cells, or all three. The 2B12 antibody staining in the oval bundle of His corresponds to a time when chick DRG axons have reached the primordium of the dorsal funiculus and then wait $24 \mathrm{~h}$ before entering the spinal cord gray matter (Davis et al., 1989). These results suggest that DRG axons may require time in vivo, just as they do in vitro, to adapt to the presence of growth inhibitory proteins (such as aggrecan) before extending beyond these growth-inhibitory areas. Inhibitory proteoglycans can promote axon fasciculation in vitro (Snow et al., 2003), suggesting that aggrecan expressed in the oval bundle of His could contribute to the fasciculation of axons in this region and thus contribute to the formation of the dorsal funiculus.

The fact that the 2B12 antibody [and the antibody used by Popp et al. (2003)] shows a staining pattern that is quite different from that observed with either the S103L (Fig. $1 F$ ) or the $1 \mathrm{G} 12$ (Fig. $2 \mathrm{~F}$ ) antibody raises the important question of precisely what antigen(s) 2B12 recognizes. By a number of criteria (Fig. 2), 2B12 seems to interact exclusively with aggrecan and to reveal aggrecan in tissues in which aggrecan message is present, yet other antibodies do not detect protein. In nanomelic chicks, 2B12 immunoreactivity associated with the oval bundle of His, peripheral nerve, and ventral spinal cord persists, whereas notochord staining is lost (Fig. $2 \mathrm{H}$ ). Previous work has shown that chondrocytes derived from chickens with the nanomelic mutation synthesize a truncated form of the aggrecan protein that is not processed or secreted (Vertel et al., 1994; Domowicz et al., 1995, 1996, 2000; Chen et al., 2002) and that S103L-aggrecan immunoreactivity is not observed in the notochord of nanomelic animals (Domowicz et al., 2003). Aggrecan is known to be differentially processed in different tissues (Domowicz et al., 1995), raising the possibility that neural tissue in nanomelic mutants may secrete a truncated form of aggrecan that is uniquely modified compared with chondrocytes. Our data suggest two possibilities: either that 2B12 rec-
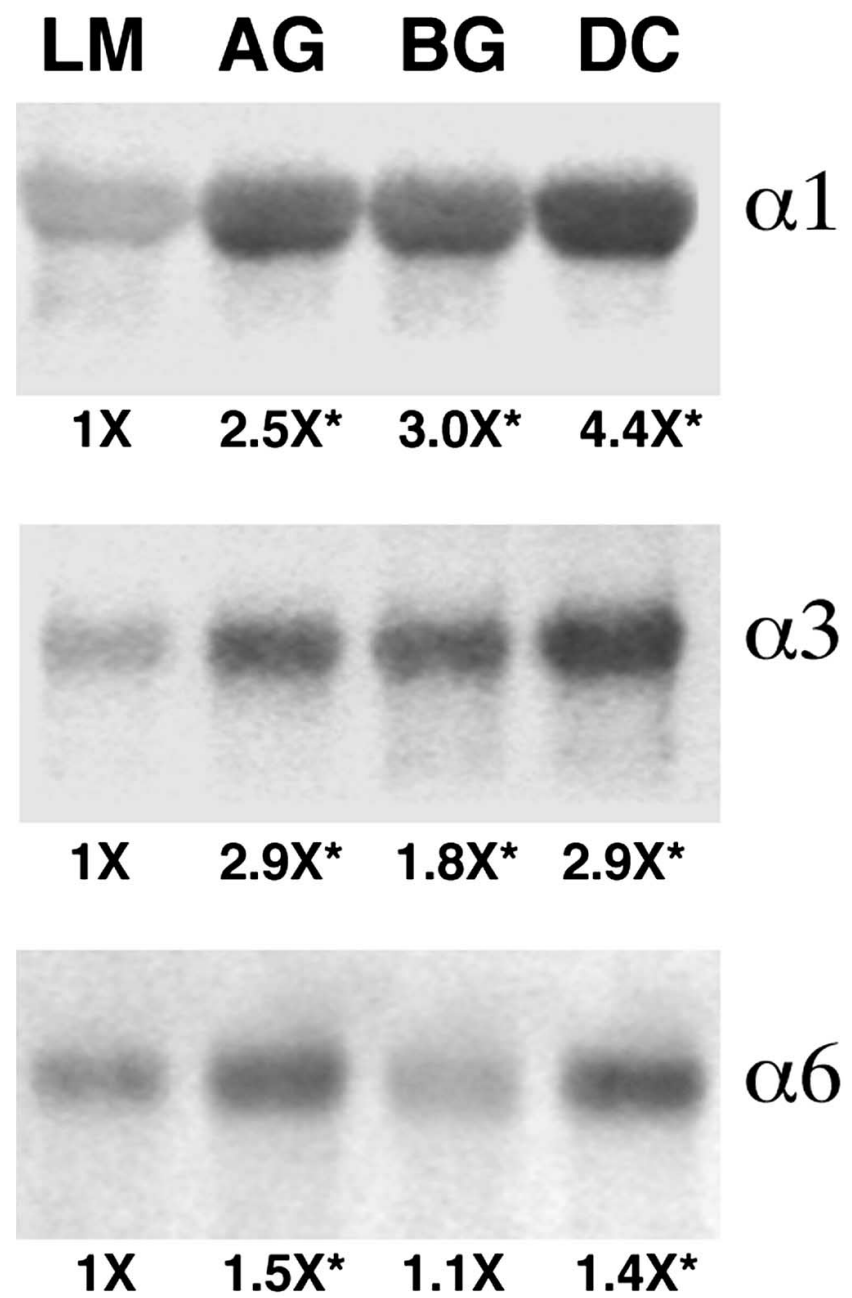

Figure 6. Laminin receptors containing integrins $\alpha 1, \alpha 3$, and $\alpha 6$ are upregulated by inhibitory proteoglycans. Neurons were cultured $20-24 \mathrm{~h}$ on laminin (LM) or laminin/proteoglycan substrata as in Figure 3. The proteoglycans tested were aggrecan (AG), biglycan (BG), and decorin (DC). Surface proteins were biotinylated and immunoprecipitated with antibodies specific for integrin $\alpha$ subunits. Biotinylated protein was detected on Western blots using HRPconjugated avidin and a chemoluminescent detection reagent. Band intensity was compared with control (laminin) conditions, and ratios from at least three independent experiments are given below the gels. All three laminin receptors are upregulated at the cell surface in the presence of proteoglycans, with the exception of integrin $\alpha 6$ on biglycan. *Statistically different from a ratio of $1(p<0.01 ; t$ test).

ognizes truncated aggrecan present in neural tissue of nanomelic animals and not notochord or that a molecule sharing antigenic sites with aggrecan is highly expressed in the spinal cord and peripheral nerve. 

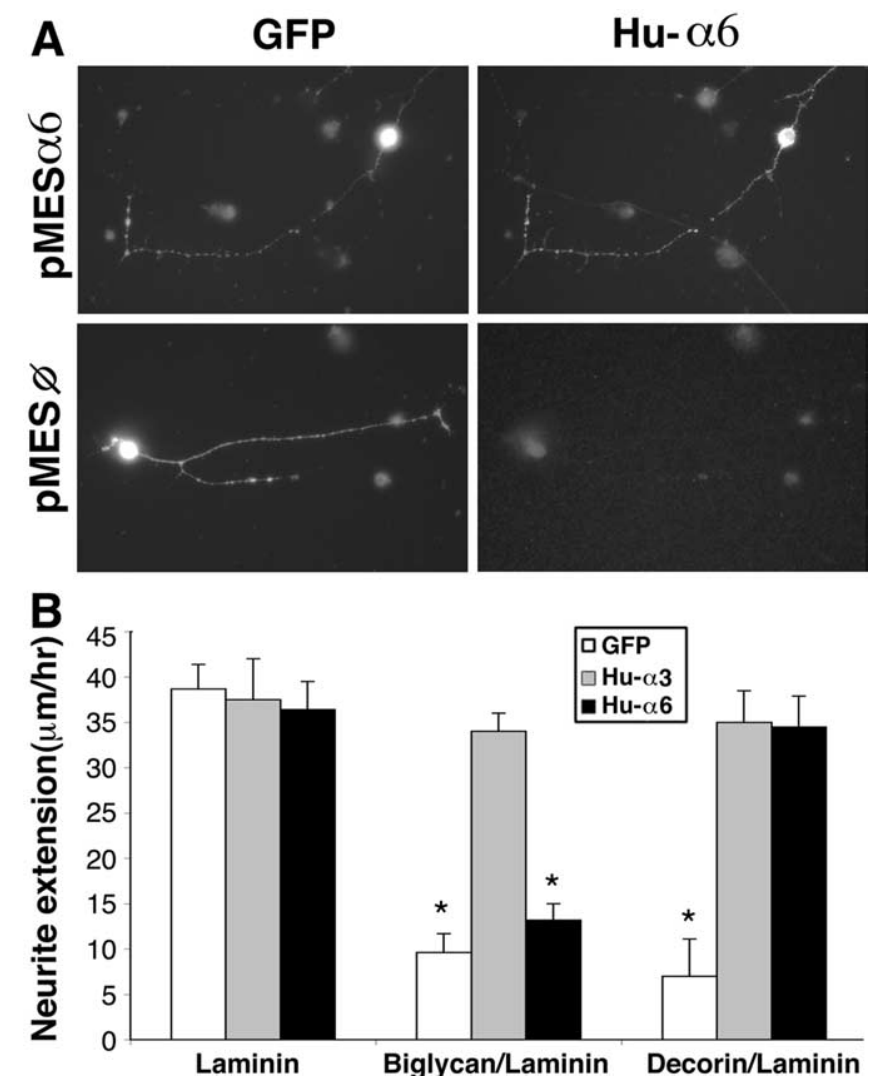

Figure 7. Increased integrin expression is sufficient for neurite extension in the presence of inhibitory proteoglycans. [The higher rates of neurite extension in these experiments compared with those of Fig. 5 are likely to reflect the longer period of time these cells were maintained in suspension before testing in short-term assays (see Materials and Methods).] $\boldsymbol{A}$, Neurons transfected with control (pMES $\phi$ ) or human integrin $\alpha 6$-containing (pMES $\alpha 6$ ) constructs are readily detected by GFP expression in culture. Integrins containing human $\alpha 6$ (right) and $\alpha 3$ (data not shown) subunits were detected at the cell surface in cultures stained live with humanspecific integrin antibodies. $\boldsymbol{B}$, At $3 \mathrm{~h}$ in culture on substrata containing either biglycan or decorin in combination with laminin, neurons expressing the control construct extended growth cones at very slow speeds, whereas cells expressing human $\alpha 3$ showed rates of extension that are identical to control cells on laminin alone. In contrast, overexpression of human $\alpha 6$ improved neurite extension on decorin substrata, where this receptor is endogenously upregulated (Fig. 6), but not on biglycan, where $\alpha 6$ levels are not normally upregulated (Fig. 6). Similar results have been published for transgenic integrin expression on aggrecan/laminin substrata (Condic et al., 1999; Condic, 2001). *Statistically different from control constructs ( $p<0.002$; $t$ test). Hu- $\alpha 6$, Human $\alpha 6$; Hu- $\alpha 3$, human $\alpha 3$.

The response of neurons to decorin-family proteoglycans Although the inhibitory function of hyalectin proteoglycans has been well documented (Bandtlow and Zimmermann, 2000; Yamaguchi, 2000), the role of decorin-family proteoglycans has been less clear (for review, see Condic and Lemons, 2002). Decorin is expressed in the CNS during development (Kappler et al., 1998) and after CNS injury (Stichel et al., 1995), as well as in the pathways of peripheral neurons (Fig. 1), yet what little is known regarding the influence of decorin on neurite outgrowth is controversial. One study examined the response of PC12 cells and DRG neurons at relatively long times in culture and determined that decorin-like molecules inhibit outgrowth on fibronectin, but not on laminin (Braunewell et al., 1995). However, another study reports that decorin suppresses expression of other CSPGs and promotes adult axon growth in vivo (Davies et al., 2004). In contrast to decorin, biglycan has been thought previously to act mainly as a neurotrophic molecule (Junghans et al., 1995; Koops et al., 1996). Biglycan inhibits the attachment of non-neuronal cells to fibronectin (Mitani et al., 2001), but the ability of this molecule to inhibit neuronal attachment and outgrowth has not been demonstrated previously. The results presented here clearly establish that both decorin and biglycan strongly inhibit the attachment and outgrowth of embryonic sensory neurons on laminin in short-term culture assays. Moreover, our findings show that embryonic neurons can adapt to these proteoglycans over time (by $20-24 \mathrm{~h}$ ) through an upregulation of specific integrins. Interestingly, decorin and biglycan regulate integrin $\alpha$ subunits differently (Fig. 6), suggesting that closely related proteoglycans can have distinct effects on integrin expression.

\section{Integrin-mediated adaptation to inhibitory proteoglycans}

Our results show that overexpression of select integrin subunits enables neurons to readily extend neurites on proteoglycancontaining substrata at a time when nontransfected or controltransfected neurons are inhibited ( $3 \mathrm{~h}$ after plating). Interestingly, not all integrin $\alpha$ subunits relieve proteoglycan-mediated inhibition, even for closely related proteoglycans such as decorin and biglycan. This observation suggests that specific integrins interact with specific proteoglycans to mediate neuronal adaptation.

The sufficiency of integrins to overcome CSPG-mediated inhibition in culture suggests that modulation of integrin expression and/or function is one of the mechanisms through which embryonic neurons are both inhibited by and adapt to proteoglycans. In many situations, growth cones avoid embryonic regions that express CSPGs, suggesting that when growth cones have alternative, more permissive substrata, they will avoid, rather than adapt to, proteoglycan-mediated inhibition. However, there are also cases in which axons extend through regions that express proteoglycans (for review, see Pearlman and Sheppard, 1996), suggesting either that inhibition is somehow modulated by other extracellular matrix components, that neurons adapt to inhibition, or both. Adaptation to CSPG-mediated inhibition may also play a role in the timing of axon extension into CSPG-expressing embryonic regions, such as the entry of sensory fibers into the dorsal horn after a delay of $24 \mathrm{~h}$ (Davis et al., 1989), a delay that could in part reflect adaptation to CSPG-mediated inhibition.

Our current observation that diverse integrins respond to diverse CSPGs strengthens the conclusion that integrin-mediated cell attachment mainly overcomes the inhibitory effects CSPGs and also suggests a link between CSPG-mediated signaling and integrin transcriptional regulation. There is evidence that CSPGs can induce sustained increases in intracellular calcium in neurons (Snow et al., 1994), suggesting a possible role for calciumdependent transcriptional regulation of integrins in the response of embryonic neurons to CSPG-mediated inhibition.

\section{Role of integrins in the inhibition of growth cone extension} Inhibitory factors have numerous downstream effects that contribute to growth cone collapse and/or arrest, including depolymerization of growth cone actin and contraction of the cytoskeleton (Gallo and Letourneau, 2004). Yet, in vivo (where integrin ligands are ubiquitous), integrin-mediated adhesion must somehow be reduced if growth cones are to release from the substratum sufficiently for collapse to occur. A growing body of work indicates many non-proteoglycan molecules that induce growth cone collapse and/or arrest modulate integrin function (Nakamoto et al., 2004). There is particularly strong evidence for a link between collapsing factors and reduced integrin function in the case of semaphorin signaling (Mikule et al., 2002; Serini et al., 
2003; Barberis et al., 2004). Integrin function is also affected by inhibitory eph-ephrin signaling (Huynh-Do et al., 1999, 2002; Zou et al., 1999, 2002; Becker et al., 2000; Davy and Robbins, 2000; Miao et al., 2000; Elowe et al., 2001; Gu and Park, 2001; Huai and Drescher, 2001; Deroanne et al., 2003). In Drosophila, integrins genetically interact with the slit-robo pathway (Stevens and Jacobs, 2002). These results strongly support the hypothesis that molecules capable of inducing growth cone collapse and/or arrest antagonize integrin-mediated cell attachment and that reduced integrin function is both an early and a required step in growth cone collapse.

The current findings show that structurally diverse proteoglycans inhibit growth cone regeneration and that embryonic neurons subsequently upregulate integrin expression to restore efficient motility. These results suggest that enhancing integrin-based attachment and motility may counteract inhibition mediated by a wide range of molecules.

\section{References}

Bandtlow CE, Zimmermann DR (2000) Proteoglycans in the developing brain: new conceptual insights for old proteins. Physiol Rev 80:1267-1290.

Barberis D, Artigiani S, Casazza A, Corso S, Giordano S, Love CA, Jones EY, Comoglio PM, Tamagnone L (2004) Plexin signaling hampers integrinbased adhesion, leading to Rho-kinase independent cell rounding, and inhibiting lamellipodia extension and cell motility. FASEB J 18:592-594.

Barres BA, Silverstein BE, Corey DP, Chun LL (1988) Immunological, morphological, and electrophysiological variation among retinal ganglion cells purified by panning. Neuron 1:791-803.

Becker E, Huynh-Do U, Holland S, Pawson T, Daniel TO, Skolnik EY (2000) Nck-interacting Ste20 kinase couples Eph receptors to c-Jun N-terminal kinase and integrin activation. Mol Cell Biol 20:1537-1545.

Blaschke UK, Hedbom E, Bruckner P (1996) Distinct isoforms of chicken decorin contain either one or two dermatan sulfate chains. J Biol Chem 271:30347-30353.

Braunewell KH, Pesheva P, McCarthy JB, Furcht LT, Schmitz B, Schachner M (1995) Functional involvement of sciatic nerve-derived versican- and decorin-like molecules and other chondroitin sulphate proteoglycans in ECM-mediated cell adhesion and neurite outgrowth. Eur J Neurosci $7: 805-814$.

Cahoon SM, Scott SA (1999) Multiple mechanisms contribute to the avoidance of avian epidermis by sensory axons. Dev Biol 208:502-512.

Challacombe JF, Snow DM, Letourneau PC (1997) Dynamic microtubule ends are required for growth cone turning to avoid an inhibitory guidance cue. J Neurosci 17:3085-3095.

Chen L, Wu Y, Lee V, Kiani C, Adams ME, Yao Y, Yang BB (2002) The folded modules of aggrecan G3 domain exert two separable functions in glycosaminoglycan modification and product secretion. J Biol Chem 277:2657-2665.

Condic ML (2001) Adult neuronal regeneration induced by transgenic integrin expression. J Neurosci 21:4782-4788.

Condic ML, Lemons ML (2002) Extracellular matrix in spinal cord regeneration: getting beyond attraction and inhibition. NeuroReport 13:A37-A48.

Condic ML, Letourneau PC (1997) Ligand-induced changes in integrin expression regulate neuronal adhesion and neurite outgrowth. Nature 389:852-856.

Condic ML, Snow DM, Letourneau PC (1999) Embryonic neurons adapt to the inhibitory proteoglycan aggrecan by increasing integrin expression. J Neurosci 19:10036-10043.

Daniloff JK, Chuong CM, Levi G, Edelman GM (1986) Differential distribution of cell adhesion molecules during histogenesis of the chick nervous system. J Neurosci 6:739-758.

Davies JE, Tang X, Denning JW, Archibald SJ, Davies SJ (2004) Decorin suppresses neurocan, brevican, phosphacan and NG2 expression and promotes axon growth across adult rat spinal cord injuries. Eur J Neurosci 19:1226-1242.

Davies SJ, Fitch MT, Memberg SP, Hall AK, Raisman G, Silver J (1997) Regeneration of adult axons in white matter tracts of the central nervous system. Nature 390:680-683.
Davis BM, Frank E, Johnson FA, Scott SA (1989) Development of central projections of lumbosacral sensory neurons in the chick. J Comp Neurol 279:556-566.

Davy A, Robbins SM (2000) Ephrin-A5 modulates cell adhesion and morphology in an integrin-dependent manner. EMBO J 19:5396-5405.

Deroanne C, Vouret-Craviari V, Wang B, Pouyssegur J (2003) EphrinA1 inactivates integrin-mediated vascular smooth muscle cell spreading via the Rac/PAK pathway. J Cell Sci 116:1367-1376.

Domowicz M, Li H, Hennig A, Henry J, Vertel BM, Schwartz NB (1995) The biochemically and immunologically distinct CSPG of notochord is a product of the aggrecan gene. Dev Biol 171:655-664.

Domowicz M, Krueger RC, Li H, Mangoura D, Vertel BM, Schwartz NB (1996) The nanomelic mutation in the aggrecan gene is expressed in chick chondrocytes and neurons. Int J Dev Neurosci 14:191-201.

Domowicz MS, Pirok III EW, Novak TE, Schwartz NB (2000) Role of the C-terminal G3 domain in sorting and secretion of aggrecan core protein and ubiquitin-mediated degradation of accumulated mutant precursors. J Biol Chem 275:35098-35105.

Domowicz MS, Mueller MM, Novak TE, Schwartz LE, Schwartz NB (2003) Developmental expression of the HNK-1 carbohydrate epitope on aggrecan during chondrogenesis. Dev Dyn 226:42-50.

Elowe S, Holland SJ, Kulkarni S, Pawson T (2001) Downregulation of the Ras-mitogen-activated protein kinase pathway by the EphB2 receptor tyrosine kinase is required for ephrin-induced neurite retraction. Mol Cell Biol 21:7429-7441.

Faissner A, Clement A, Lochter A, Streit A, Mandl C, Schachner M (1994) Isolation of a neural chondroitin sulfate proteoglycan with neurite outgrowth promoting properties. J Cell Biol 126:783-799.

Fernandez MS, Dennis JE, Drushel RF, Carrino DA, Kimata K, Yamagata M, Caplan AI (1991) The dynamics of compartmentalization of embryonic muscle by extracellular matrix molecules. Dev Biol 147:46-61.

Fichard A, Verna J-M, Olivares J, Saxod R (1991) Involvement of a chondroitin sulfate proteoglycan in the avoidance of chick epidermis by dorsal root ganglia fibers: a study using b-D-xyloside. Dev Biol 148:1-9.

Fitch MT, Silver J (1997) Glial cell extracellular matrix: boundaries for axon growth in development and regeneration. Cell Tissue Res 290:379-384.

Fransson LA, Belting M, Jonsson M, Mani K, Moses J, Oldberg A (2000) Biosynthesis of decorin and glypican. Matrix Biol 19:367-376.

Gallo G, Letourneau PC (2004) Regulation of growth cone actin filaments by guidance cues. J Neurobiol 58:92-102.

Gates MA, Fillmore H, Steindler DA (1996) Chondroitin sulfate proteoglycan and tenascin in the wounded adult mouse neostriatum in vitro: dopamine neuron attachment and process outgrowth. J Neurosci 16:8005-8018.

Gu C, Park S (2001) The EphA8 receptor regulates integrin activity through p110gamma phosphatidylinositol-3 kinase in a tyrosine kinase activityindependent manner. Mol Cell Biol 21:4579-4597.

Halfter W, Yip YP, Yip JW (1994) Axonin 1 is expressed primarily in subclasses of avian sensory neurons during outgrowth. Brain Res Dev Brain Res 78:87-101.

Halfter W, Schurer B, Yip J, Yip L, Tsen G, Lee JA, Cole GJ (1997) Distribution and substrate properties of agrin, a heparan sulfate proteoglycan of developing axonal pathways. J Comp Neurol 383:1-17.

Herbst TJ, McCarthy JB, Tsilibary EC, Furcht LT (1988) Differential effects of laminin, intact type IV collagen, and specific domains of type IV collagen on endothelial cell adhesion and migration. J Cell Biol 106:1365-1373.

Huai J, Drescher U (2001) An ephrin-A-dependent signaling pathway controls integrin function and is linked to the tyrosine phosphorylation of a 120-kDa protein. J Biol Chem 276:6689-6694.

Huynh-Do U, Stein E, Lane AA, Liu H, Cerretti DP, Daniel TO (1999) Surface densities of ephrin-B1 determine EphB1-coupled activation of cell attachment through alphavbeta 3 and alpha5betal integrins. EMBO J 18:2165-2173.

Huynh-Do U, Vindis C, Liu H, Cerretti DP, McGrew JT, Enriquez M, Chen J, Daniel TO (2002) Ephrin-B1 transduces signals to activate integrinmediated migration, attachment and angiogenesis. J Cell Sci 115:3073-3081.

Jentoft N, Dearborn DG (1979) Labeling of proteins by reductive methylation using sodium cyanoborohydride. J Biol Chem 254:4359-4365.

Junghans U, Koops A, Westmeyer A, Kappler J, Meyer HE, Muller HW (1995) Purification of a meningeal cell-derived chondroitin sulphate 
proteoglycan with neurotrophic activity for brain neurons and its identification as biglycan. Eur J Neurosci 7:2341-2350.

Kappler J, Stichel CC, Gleichmann M, Gillen C, Junghans U, Kresse H, Muller HW (1998) Developmental regulation of decorin expression in postnatal rat brain. Brain Res 793:328-332.

Koops A, Kappler J, Junghans U, Kuhn G, Kresse H, Muller HW (1996) Cultured astrocytes express biglycan, a chondroitin/dermatan sulfate proteoglycan supporting the survival of neocortical neurons. Brain Res Mol Brain Res 41:65-73.

Landolt RM, Vaughan L, Winterhalter KH, Zimmermann DR (1995) Versican is selectively expressed in embryonic tissues that act as barriers to neural crest cell migration and axon outgrowth. Development 121:2303-2312.

Lemons ML, Howland DR, Anderson DK (1999) Chondroitin sulfate proteoglycan immunoreactivity increases following spinal cord injury and transplantation. Exp Neurol 160:51-65.

Lemons ML, Sandy JD, Anderson DK, Howland DR (2001) Intact aggrecan and fragments generated by both aggrecanse and metalloproteinase-like activities are present in the developing and adult rat spinal cord and their relative abundance is altered by injury. J Neurosci 21:4772-4781.

Lemons ML, Sandy JD, Anderson DK, Howland DR (2003) Intact aggrecan and chondroitin sulfate-depleted aggrecan core glycoprotein inhibit axon growth in the adult rat spinal cord. Exp Neurol 184:981-990.

Lennon DP, Carrino DA, Baber MA, Caplan AI (1991) Generation of a monoclonal antibody against avian small dermatan sulfate proteoglycan: immunolocalization and tissue distribution of PG-II (decorin) in embryonic tissues. Matrix 11:412-427.

Li H, Schwartz NB, Vertel BM (1993) cDNA cloning of chick cartilage chondroitin sulfate (aggrecan) core protein and identification of a stop codon in the aggrecan gene associated with the chondrodystrophy, nanomelia. J Biol Chem 268:23504-23511.

Maeda N, Noda M (1996) 6B4 proteoglycan/phosphacan is a repulsive substratum but promotes morphological differentiation of cortical neurons. Development 122:647-658.

McKeon RJ, Hoke A, Silver J (1995) Injury-induced proteoglycans inhibit the potential for laminin-mediated axon growth on astrocytic scars. Exp Neurol 136:32-43.

Miao H, Burnett E, Kinch M, Simon E, Wang B (2000) Activation of EphA2 kinase suppresses integrin function and causes focal-adhesion-kinase dephosphorylation. Nat Cell Biol 2:62-69.

Mikule K, Gatlin JC, de la Houssaye BA, Pfenninger KH (2002) Growth cone collapse induced by semaphorin $3 \mathrm{~A}$ requires 12/15-lipoxygenase. J Neurosci 22:4932-4941.

Milev P, Chiba A, Haring M, Rauvala H, Schachner M, Ranscht B, Margolis RK, Margolis RU (1998) High affinity binding and overlapping localization of neurocan and phosphacan/protein-tyrosine phosphatase-zeta/ beta with tenascin-R, amphoterin, and the heparin-binding growthassociated molecule. J Biol Chem 273:6998-7005.

Mitani Y, Honda A, Jasin HE (2001) Polymorphonuclear leukocyte adhesion to articular cartilage is inhibited by cartilage surface macromolecules. Rheumatol Int 20:180-185.

Nakamoto T, Kain KH, Ginsberg MH (2004) Neurobiology: new connections between integrins and axon guidance. Curr Biol 14:R121-R123.
Pearlman AL, Sheppard AM (1996) Extracellular matrix in early cortical development. Prog Brain Res 108:117-134.

Popp S, Andersen JS, Maurel P, Margolis RU (2003) Localization of aggrecan and versican in the developing rat central nervous system. Dev Dyn 227:143-149.

Serini G, Valdembri D, Zanivan S, Morterra G, Burkhardt C, Caccavari F, Zammataro L, Primo L, Tamagnone L, Logan M, Tessier-Lavigne M, Taniguchi M, Puschel AW, Bussolino F (2003) Class 3 semaphorins control vascular morphogenesis by inhibiting integrin function. Nature 424:391-397.

Silver J, Miller JH (2004) Regeneration beyond the glial scar. Nat Rev Neurosci 5:146-156.

Snow DM, Letourneau PC (1992) Neurite outgrowth on a step gradient of chondroitin sulfate proteoglycan (CS-PG). J Neurobiol 23:322-336.

Snow DM, Lemmon V, Carrino DA, Caplan AI, Silver J (1990) Sulfated proteoglycans in astroglial barriers inhibit neurite outgrowth in vitro. Exp Neurol 109:111-130.

Snow DM, Atkinson PB, Hassinger TD, Letourneau PC, Kater SB (1994) Chondroitin sulfate proteoglycan elevates cytoplasmic calcium in DRG neurons. Dev Biol 166:87-100.

Snow DM, Smith JD, Cunningham AT, McFarlin J, Goshorn EC (2003) Neurite elongation on chondroitin sulfate proteoglycans is characterized by axonal fasciculation. Exp Neurol 182:310-321.

Stevens A, Jacobs JR (2002) Integrins regulate responsiveness to slit repellent signals. J Neurosci 22:4448-4455.

Stichel CC, Kappler J, Junghans U, Koops A, Kresse H, Muller HW (1995) Differential expression of the small chondroitin/dermatan sulfate proteoglycans decorin and biglycan after injury of the adult rat brain. Brain Res 704:263-274.

Strachan LR, Condic ML (2004) Cranial neural crest recycle surface integrins in a substratum-dependent manner to promote rapid motility. J Cell Biol 167:545-554.

Streit A, Nolte C, Rasony T, Schachner M (1993) Interaction of astrochondrin with extracellular matrix components and its involvement in astrocyte process formation and cerebellar granule cell migration. J Cell Biol 120:799-814.

Thiery JP, Delouvee A, Grumet M, Edelman GM (1985) Initial appearance and regional distribution of the neuron-glia cell adhesion molecule in the chick embryo. J Cell Biol 100:442-456.

Vertel BM, Grier BL, Li H, Schwartz NB (1994) The chondrodystrophy, nanomelia: biosynthesis and processing of the defective aggrecan precursor. Biochem J 301:211-216.

Yamada H, Watanabe K, Shimonaka M, Yamaguchi Y (1994) Molecular cloning of brevican, a novel brain proteoglycan of the aggrecan/versican family. J Biol Chem 269:10119-10126.

Yamaguchi Y (2000) Lecticans: organizers of the brain extracellular matrix. Cell Mol Life Sci 57:276-289.

Zou JX, Wang B, Kalo MS, Zisch AH, Pasquale EB, Ruoslahti E (1999) An Eph receptor regulates integrin activity through R-Ras. Proc Natl Acad Sci USA 96:13813-13818.

Zou JX, Liu Y, Pasquale EB, Ruoslahti E (2002) Activated SRC oncogene phosphorylates R-ras and suppresses integrin activity. J Biol Chem 277: $1824-1827$. 